\title{
Mergers and Acquisitions in the EU low cost carrier market. A Product and Organisation Architecture (POA) approach to identify potential merger partners.
}

\author{
Lenartowicz, M., Mason, K*., and A. Foster \\ Cranfield University, UK \\ *Corresponding Author k.mason@cranfield.ac.uk
}

\begin{abstract}
As the EU low cost airline sector matures, consolidation is expected. This paper details a threestage methodology to examine LCCs mergers and acquisition activity. A series of depth interviews with aviation experts concludes that the motives for LCCs to enter mergers and acquisitions are largely similar to those of full service carriers. A key success factor for merging partners is to have similar business models and culture. An analysis of full service and low cost carrier mergers and acquisition activity events shows that the size ratio and degree of network overlap between merging airlines are also independent of airline type. Braxton and BCG analyses of EU LCCs show Ryanair and EasyJet to be the only LCCs in the market with strong strategic positions across the markets they serve. Finally, an application of the Product and Organisation Architecture analytical approach was used to compare seven EU LCCs. EasyJet and Vueling were found to have the most similar business models and were therefore considered the best strategic fit for a potential merger.
\end{abstract}

\section{Introduction}

Since the 1980's, two important aviation trends have dominated air transport research: airline market consolidation and the growth of low-cost carriers. However, very little research has considered the merger and acquisition activity of low cost airlines. This paper sets out to address merger and acquisition activity within the LCC sector with a focus on the EU market.

The liberalisation of the intra-EU air services market provided the legislative framework in which low cost carriers (LCCs) could develop. The 'Third Package' of aviation measures came into force in January 1993, with full cabotage following in 1997. This market liberalisation allowed airlines to operate between any points in the European Union (EU). These new regulations have had a similar effect to the deregulation of the US domestic market some twenty years earlier. US deregulation saw the establishment and growth of Southwest Airlines, the archetypal low cost carrier.

Ryanair was the first EU airline to take advantage of the new European regulatory environment. The company based its strategy on the successful Southwest model, which quickly proved to work perfectly well in Europe. Soon after, start-ups like EasyJet and Debonair also launched low-cost services. Many legacy carriers reacted to the threat of low-fare airlines by establishing their own LCC subsidiaries (including BA's Go and KLM's Buzz), yet, most did not succeed (Francis et al. 2005). After a few years, the market went through an initial wave of consolidation. 
Market leaders Ryanair and easyJet both acquired smaller competitors, Buzz and Go respectively, whilst many other small carriers collapsed (Danklefsen, 2007). By 2011, one hundred and ten low cost carriers had entered the EU market but only thirty-two survived (Mason, et al., 2013). The rest had either gone out of business, been acquired or had merged with a competitor.

Mergers and acquisitions (M\&A) are means of rapidly achieving external corporate expansion and growth (Tickle 1987). As companies merge, their resources are conjoined to increase the value in the combined business. The sources of added value are synergies found either on the revenue or cost side of the business. Revenue enhancements can be achieved in a merged company through the growth in scale of the business (Dobson and Piga, 2009), increased market power, increased product attractiveness, or access to scarce resources. Sources for cost synergies include removal of overlapping areas, efficiency gains (economies of scale, scope, density and learning), and tax benefits (Maruna 2008, Merkert and Morrell 2012).

Historically, global M\&A activity has tended to follow patterns of "waves", with periods of increased M\&A activity, followed by periods of relative steadiness or declines (Sudarsanam 2003). Wang (2012) found airline merger activity tended to be cyclical and one significantly large merger may trigger a number of others in a region. The consensus view of a number of airline experts was that only two or three large low cost carriers will dominate the European market by 2015 (Mason and Alamdari, 2007). The consolidation trend towards a limited number of big LCC was also highlighted by Danklefsen (2007) in a study for the European Parliament and by Graham and Shaw (2008)

Whilst mergers offer opportunities to raise revenue and reduce costs, such opportunities are not automatically realised. Post-merger integration is the most crucial phase in the airlines' merger, considering strategic fit, revenue and cost synergies and cultural fit as the more important parameters for a successful merger (Maruna, 2008). Hanson et al. (2002) highlighted a number of reasons for failure of airline mergers including poor planning and execution, complexities caused by the labour component of the merger, and lack of familiarization with the business model of acquired company

Over the past three decades analysis of airline consolidation as a function of deregulation and liberalisation, and the expansion of LCC sector, have developed parallel to one another. However, as the LCC sector is maturing, consolidation among this group of airlines is expected. There is lack of the systematic research on mergers of low cost carriers. Here we consider whether LCC mergers differ in any substantive way from the merger of full service carriers and to look at the likelihood of merger activity in the EU market and which carriers are most likely to be involved in such activity.

\section{Methodology}

To investigate mergers and acquisition impacts a multi-stage methodology is employed.

A panel of ten aviation experts were interviewed between May and July 2012 to gather opinions from a variety of aviation professionals with experience in LCC mergers. These included three 
managing directors of aviation consultancies, three directors of LCCs, and four senior managers at LCCs. There was a focus to interview respondents who were involved in one of the following mergers: Ryanair/Buzz, easyJet/Go or Vueling/Clickair. Despite several attempts, contact with Ryanair could not be established. Respondents were asked a series of open-ended questions regarding the reasons for an airline to merge with or acquire another airline, the key characteristics of a target partner and issues that may impact the success of a merger. The responses were un-prompted. Following the interviews the responses to each question were categorised and frequencies calculated to identify the key responses to each question. The responses gaining three or more un-prompted responses were considered to be important.

To identify the general patterns of low-cost carriers M\&As, recent airline mergers were analysed. Thirty-nine airline mergers (including both full service and LCC) were identified and investigated with respect of the relative size of the airlines merged, and the extent of network overlap. An airline's network structure is an essential feature for distinguishing low-cost airlines from traditional carriers. Dobruszkes (2006) provided a detailed analysis of the network structures of European LCC and provides an important framework analysing an airline's size and network. The M\&A incidents investigated occurred between the Southwest's acquisition of Morris Air in 1993 and concluding with Southwest's merger with Air Tran in 2011. A full list of mergers/acquisitions is listed in Appendix 1.

Data for the analysis of the size and network was drawn from the Official Airline Guide database (FlightGlobal, 2012), which provides a detailed and disaggregated description of the airlines' supply of capacity. For each merger data were collected on: the acquirer: operations (aircraft movements), seats and ASKs, the target airline: operations, seats and ASKs, and network overlap: airports served, routes and seats on overlapping routes

For analyses, each metric was examined but an aggregated single measure, which would take into account both the differences in aircraft size and the stage length is preferred. As a consequence, an airline size parameter is developed for each airline engaged in a merger:

$$
\text { Aggregated Airline Size }=\sum \text { OPS } / 10^{3}+\text { Seats } / 10^{6}+A S K / 10^{9}
$$

The powers applied to each item reflect the difference in magnitude of each metric. Subsequently, a size ratio for each merger was calculated, to assess the relative size of merger partners to each other. (The acquirer always refers to the larger airline, however in some cases, the merged entities used the name of the smaller partner.)

Size ratio $=\frac{\text { Aggregated } \text { Target Size }}{\text { Aggregated Acquirer Size }}$

Network Overlap was the final parameter to be assessed. There were various measures that could have been used to express this value. Overlap is assessed by looking at three items: airports, routes and network seats. 
Airport Overlap is the number of airports operated by both airlines divided by the number of airports served by both airlines. Routes Overlap indicates the number of routes (O-D) were carriers compete, in relation to number of routes being operated. Finally, the Seats Overlap seeks to explain how many seats are being operated on the overlapping routes. Each parameter implies important operational consequences for the merging airlines. For example, the high Airport Overlap, means that facilities and services might be shared. The Routes Overlap illustrates how the network may expand after a merger, while the Seats Overlap describes how direct competition between two airlines might change. Finally Network Overlap was calculated as the mean of the three previous components. The following equations provide the methodology of Network Overlap calculations:

$$
\begin{aligned}
& \text { Airport Overlap }=\frac{\text { Airports served by both carriers }}{\text { Airports served by at least one carrier }} \\
& \text { Routes Overlap }=\frac{\text { Routes served by both carriers }}{\text { Routes served by at least one carrier }} \\
& \text { Seats Overlap }=\frac{\text { Seat served on overllaping routes }}{\text { All seats served by both carriers }} \\
& \text { Network Overlap }=\frac{\text { Airports Overlap }+ \text { Routes Overlap }+ \text { Seats Overlap }}{3}
\end{aligned}
$$

Following the analysis of the relative size and degree of network overlap, an analysis of the strategic need for an airline to merge was examined. Merger activity may be expected when a market reaches maturity and therefore provides limited potential for organic growth. At this stage, mergers provide an opportunity to achieve the size, economies of scale and market power needed to compete with equally strong competitors (Tickle 1987).

To examine the market situation with respect to market development both Braxton and Boston Consulting Group analyses were conducted. Both approaches place emphasis on the competitive dynamics of the industry. For each analysis the market growth rate and relative market share were examined. Growth was assessed by examining the annualised average increase in available seats from 2006 to 2011. The relative market share was examined in 2011. The data required to develop the analyses were obtained from the OAG. To examine the markets for each low cost carrier, the European market was divided into seven approximately equally sized geographical regions (Table 1).

\section{Table 1 about here}

Strategic fit is an important factor during a merger partner/acquisition target airline partner selection process, and to investigate which airlines would be a good fit with each other, the key elements of airlines' business models need to be identified and compared. The applicability of 
using Mason and Morrison's (2009) Product and Organizational Architecture ${ }^{1}$ approach in the partner identification process was investigated to see whether it is a suitable approach to compare strategic fit for merger partners. This was undertaken using ex-post analysis of the Southwest and AirTran merger, and the approach selected to conduct an ex-ante analysis of the key LCCs in Europe.

The POA analysis covers two sets of data: 2010 US low-cost carriers and 2011 European lowcost carriers. The sample from US includes seven biggest players: Southwest, AirTran, JetBlue, Frontier, Spirit, Allegiant and Virgin America. The sample of EU airlines includes: Ryanair, easyJet, airberlin, Norwegian, Vueling Airlines, Aer Lingus and flybe.

The following weights (Table 2) were applied to the benchmark items. The weights as previously explained in Mason and Morrison (2009) are based on the correlation of each benchmark item against profitability. The data used to calculate these weights include the US 2010 data, the EU 2011 data and also the dataset used to calculate the weights included in the earlier study. These new weights reflect a greater data set than was used in Mason and Morrison (2009). The highlighted figures represent the items that have the greatest impact on LCC profitability.

\section{Table 2 about here}

To examine the strategic fit of the airlines for potential merger or acquisition a Similarity Index was developed. The application of the POA model means that the business models of potential merger partners may be expressed numerically. Once the final index scores for each airline are calculated, the carriers can be easily compared. To find which airlines have the most similar business models, the index score differences in each category were calculated. The sum of differences gives the Similarity Index Score as shown in Equation 7. It is assumed, that the smaller the Similarity Index Score, the easier two airlines can integrate into one unit.

Similarity Index Score $A B=\sum_{i=1}^{n} \mid$ Airline $A \operatorname{Index}_{i}-$ Airline $B \operatorname{Index}_{i} \mid$

To test the validity of using the POA model and the Similarity Index to examine potential merger partners strategic fit, a post-ante examination of the business models of Southwest and Air Tran prior to their merger in 2011.

Figure 1 about here

From the diagram the differences between the business models of merging partners can be visually identified. To measure the differences more precisely the difference for each index score for the two airlines was calculated and summated. The overall Similarity Index score was calculated as 22.8. The highest contribution to the overall difference comes from connectivity

\footnotetext{
${ }^{1}$ The POA business model analytical tool is based on "best-in-class" benchmark comparisons of all airlines within an analysis. Full details of the methodology and application can be found in Mason and Morrison (2009).
} 
which is not surprising given that Southwest, with nearly 1,000 routes, has three times as many as the next largest airline in the analysis.

The use of the POA model facilitates the comparison of the merger partners and helps to identify the areas that might be difficult to integrate. For Southwest/AirTran none of these were real threats to the success of the merger. Many of the other differences between Southwest and Air Tran, especially the aircraft and comfort indices, are because AirTran uses the smaller Boeing 717. Within months after the merger a decision about a transition to a single aircraft type was released (FlightGlobal 2012).

Table 3 about here

The same method of comparison was employed to examine all the possible merger combinations. For Southwest Airlines, AirTran was the airline with the closest business model fit, although JetBlue might also be a future target. The results provide verification of the proposition, that POA model might be successfully used to find the most suitable airline partners and consequently it was decided to use this approach to examine potential merger partners in the EU LCC market.

\section{Results}

Expert interviews on LCCs and $M \& A$ activity.

Ten experts in LCC M\&A activity were interviewed to explore some key areas of low-cost carriers mergers. Asked the principal reasons an LCC may seek to merge with a potential partner or acquire a competitor, the respondents indicated that network growth, to remove competition, gain access to new markets, and relieve economic pressure were the main drivers. The responses were un-prompted and the table shows the number of respondents who mentioned each item. Only items that were mentioned by three or more of the experts were included in Figure 2.

Figure 2 about here

When asked to identify the key characteristics of any potential merger partner or acquisition target, the industry experts highlighted fleet compatibility, business culture and network advantages as the most important. Experts concluded that airlines should primarily search for business model fit and network characteristics of the potential merger partner (Figure 3). These findings are consistent with those of Maruna (2008) who investigated the topic of airline mergers in general.

Figure 3 about here

The experts were then asked to name key sources of synergy as two LCCs merge. They indicated that head-office rationalisation, network optimisation and leveraging greater purchasing power were the principal benefits. Only two respondents mentioned higher yields or load factors. When 
asked for possible future scenarios for the EU LCC sector, the greatest number of un-prompted responses was for a view that consolidation in the sector was expected.

\section{Network size and merger analysis}

An analysis of 39 full service and low cost carrier merger or acquisitions was used to examine patterns in airline M\&A activity and identify any differences in merger activity between the airline types.

It is not surprising that mergers between full service carriers were identified as being between larger carriers than those between low cost carriers ${ }^{2}$. The full service carriers (FSCs) acting as acquirers were on average 50\% larger in comparison with low-cost carriers that acquired or merged with other LCCs. The same trend was observed among those airlines targeted for acquisition. On average the targets of LCC mergers were three times smaller than airlines that were bought by full-service carriers. This analysis was conducted on the aggregate size metric developed in the methodology. Tests conducted across operations, seats, and ASKs, for both acquirers and targets produced similar results, giving some confidence that the metric is an adequate aggregate measure of an airline's size. It seems possible that the difference in size is more likely a result of the maturity of both types of airlines. Full-service carriers operate in more mature, less fragmented markets, in line with the qualitative results of the interviews.

An airline's business model was shown to have no impact on the average size ratio of a target airline to its acquirer. The ratio of the target and acquirer airlines, at 0.42 , is not affected by the airline's business model, with the average ratio being statistically similar for both low-cost and network carriers. Table 4 provides a summary of the size parameters of the analysed mergers between low-cost carriers, including the size ratios between acquirer airline and target. The mergers were classified in regard to the size ratio of merging partners (Sudrasanam, 2003). A "Takeover" is where there is a great difference in size between the two airlines (ratio< 0.16 ). Most of the cases were categorised as an "acquisition" where the target company became incorporated by the acquirer. Only a few examples could be classified as a "merger of equals" where the size ratio was higher than 0.70 .

Table 4 about here

Network overlap is one of the most important factors to be considered during merger evaluation (Maruna 2008, Iatrou and Oretti 2007). Again a series of t-tests were conducted on network overlap, airport overlap, and routes and seats overlaps and no statistical differences were found between full service and low cost airlines. The average network overlap of the sample was 0.15 , however, the values were reasonably equally distributed across a range between 0.05 and 0.25. Table 5 summarises the network overlap of the low-cost carrier mergers in the sample set. It can be seen, that the network overlap was not the main motive for easyJet and Ryanair's acquisitions. Indeed experts who were engaged in these mergers, stated that access to the slots at Gatwick and

\footnotetext{
${ }^{2}$ A two-tailed t-test found a significant difference in the size of merging partners depending on the operating model (full service airline or LCC).
} 
Stansted respectively was the main trigger for both transactions. In contrast, the merger of ClickAir and Vueling was rather different. Before consolidation, these two airlines were the biggest competitors in Barcelona airport but neither was profitable. "Previous failing business route" is one of the methods to persuade authorities to support a merger decision (Fageda and Perdiguero, 2011, Fragkogianni, 2012). These airlines gained the approval to integrate their services in 2009 even with their high network overlap, however, the European Commission conditioned its decision on the number of remedies including giving up some of their landing slots. The Commission believed that these remedies were likely to facilitate entry for other competitors, thus maintaining competitive pressure on the merged entity (EC, 2009).

Table 5 about here

\section{Strategic fit analysis of EU LCCs merger partners}

The expansion of LCCs in Europe developed quickly following the full liberalisation of the market in 2001, some 20 years after a similar trend occurred in the United States. The European market is far less concentrated than the US. The three biggest players, namely Ryanair, easyJet and airberlin jointly supply over half of the seats, whereas in the United States the market share of the largest three LCCs exceeds $80 \%$. However, the European low-cost airline market is gradually maturing (Francis et al., 2005, de Wit and Zuidberg, 2012). According to the industry life cycle hypothesis, when a market approaches the maturity stage, increased levels of M\&A activity might occur. It is therefore possible that a wave of mergers may occur in the EU airline sector as it matures.

To examine the possible outcome of such a round of M\&A activity in the EU LCC market, it is necessary to investigate whether the studied airlines have potential reasons for entering a merger. According to the expert depth interviews the main motives pushing low-cost airlines to merge are for growth, competitive position, to gain access to markets and economic pressure. The position of a number of EU LCCs has been examined in these areas.

Figure 4 illustrates a Braxton analysis of the relative performance of the nine largest European low cost carriers. Three groups of airlines can clearly be seen. The first group consists of "market leaders' (Ryanair, EasyJet and Air Berlin). During the 2006-2011 period the three biggest carriers grew approximately at the average rate for the industry. The second group covers the 'followers'. These airlines (Nowegian, Vueling and Aer Lingus), although smaller in size, were growing much quicker than the rest of the industry. The remaining airlines (Wizz, Flybe, and germanwings), did not grow much, focusing on niche markets (Eastern Europe, regional and German leisure markets respectively).

Figure 4 about here

To analyse the competitive position of each airline, a Boston Consulting Group analysis was conducted on the sample airlines. The services of each airline in seven European markets were calculated (refer to table 1 for the classification of the regions). Table 6 provides details of the 
relative market share of each airline in a particular market, while Table 7 illustrates each airline's growth in 2010/11.

Table 6 about here

Table 7 about here

The Boston Consulting Group Product Portfolio Matrix can be used to develop appropriate strategies for the business streams a company has. In theory, 'cash cows' (that enjoy high market share but in low growth markets) are the products that offer the highest returns and do not requiring significant additional investment. To achieve the sustainable position, companies should try to have a balanced portfolio, consisting of 'cash cows', 'stars' (potential 'cash cows' of the future) and some 'question marks' (investment support may enable these to be the 'stars' of the future).

Figure 5 about here

Figure 5 illustrates an application of the product portfolio to Ryanair's business by regions. It can be noticed that the airline has a very strong position in the UK region. In 2011, the output of 'Star' products was increased by approximately $20 \%$, while the number of seat from East Europe region increased by $5 \%$. At the same time, Ryanair reduced the number of flights to Germany region by one quarter, possibly in response to high competition or perhaps increased costs. Regarding the two reaming regions, the airline maintained its status quo. The competitive situation for easyJet is illustrated in Figure 6. Apart of their home market, the airline does not have a particularly strong position in any of the regions. Yet, in 2011, easyJet increased its presence in each market, focusing the growth in France and Germany, where Ryanair has a weaker position.

Figure 6 about here

None of the other airlines had a significant position in more than one region, which would justify the production of a separate BCG graph. Instead, all of them were displayed in the one matrix highlighting each airline's position in its largest market. As can be seen in the Figure 7, none of the airlines have 'cash cow' products in their product portfolios.

Figure 7 about here

According to the industry experts, an airline's financial situation is one of the key drivers for a carrier to merge. In, 2009 two failing airlines, Vueling and Clickair merged into one entity. Since the merger, the combined airline has remained profitable. Table 8 summarises the market position and operating ratio of the sample airlines along with and possible strategic options for their markets. Where airlines are losing money, it is more likely that they will be in a weaker position, and may become an acquisition target. 
Given the size and its strong position in the European market, it is not very likely that Ryanair would benefit from a merger with any smaller and weaker carrier. In the long term though, the airline could benefit from a merger with Aer Lingus. This merger would give the Ryanair access to resources and "know-how" needed to start long haul operations if the short haul market becomes saturated. Yet, a merger between these two carriers is unlikely, as the European Commission has prohibited it due to the likely reduced levels of competition in the Irish market.

EasyJet has probably the highest motivation to grow through the merger. Despite being the second biggest low-cost carriers airline, it still has not managed to secure a high market share in many of its markets. The acquisition of a local leader could considerably strengthen its position.

The assessment of the competitive position of airberlin is rather complicated. According to Klophaus et al. (2012) the airline's business model is very close to that of a full-service carrier. During an expert interview, Doganis noted that airberlin should not be considered as a low-cost carrier anymore. The fact that the airline joined the oneworld alliance further support this hypothesis. Moreover, 29.21\% of airberlin is now owned by the Etihad (FlightGlobal Pro, 2012). Consequently, it seems unlikely that airberlin will engage in a merger with any LCC in the near future.

Norwegian, Vueling and WIZZ Air appear to be three well run, low-cost airlines. However, all of them are geographically constrained. According to the experts' opinion none of those airlines have the scale or resources to be an important player at the European level. Thus it is very likely that these airlines will be the potential targets or partners during the approaching consolidation.

The results of the strategic analysis suggest that that Aer Lingus, flybe and germanwings are not in a position to be market leaders, focusing instead on their particular niche markets. Similar opinions were offered in the expert depth interviews. One respondent gave the opinion that germanwings is a tactical project of Lufthansa, developed as a response to the low-cost carrier threat, rather than a strategic unit, focused on expansion.

\section{Table 8 about here}

The in-depth interviews with industry experts suggested business model fit is the most important factor during the partner selection process. To assess the possible merger partners in the EU LCC market, the similarity of the airlines' business models were examined. The Product and Organisation Architecture approach was used to systematically and numerically assess the business model of each of the sample airlines and a Similarity Index calculated for each potential merger pair (Table 9). Regrettably, the complete data for WIZZ Air and germanwings could not be gathered, thus these airlines could not be included in the analysis.

To find the airlines with most similar business models, the similarity matrix was developed. The lower the index value, the POA suggests the more similar the two airline business models are to one another. 
Table 9 about here

It can be seen from the data in Table 10 that easyJet, Norwegian and Vueling have the most similar business models. This also accords with the earlier observations, which showed that these carriers have the strongest motives to merge. Whilst these three airlines have the most similar business models, Air Berlin is also evaluated as being as similar to EasyJet and Norwegian as Southwest was to Air Tran. However, given its recent moves towards a full service approach (joining an alliance, and gaining financial support from Etihad) that it is unlikely to pursue a merger with a LCC partner.

Table 10 about here

Figure 8 shows POA profile of EasyJet, Norwegian and Vueling. It is apparent that the most of the differences between these airlines steams from the Connectivity and Airport Indices. This is a result of the discrepancy of network sizes. EasyJet operates much larger networks, which strongly affects the result. Norwegian and Vueling are jointly the leaders in terms of distribution cost. However, those airlines operate mostly locally, thus do not have to invest so much to be recognized in the wider market. Nevertheless, neither of these differences would critically affect the merger decision.

The labour issues during the merger are one of the greatest challenges. Thus, it is particularly important that the Labour Index scores of potential partners are quite similar.

Figure 8 about here

The conducted analyses allowed suggest easyJet and Vueling have the highest potential to merge with each other. For easyJet, the potential merger would help to develop the strong position in the Iberia region, while Vueling would benefit from the efficiency gains and higher market power. The two airlines have very similar brand position and business models. They also operate the same fleet of Airbus A320. The similarity in business model would facilitate the smooth integration. Moreover, easyJet has already had the experience in the growth through the mergers. Thus, it could take advantage of the valuable "know-how", which would help to avoid the pitfalls during the process. The approval issues should not be a major problem as the network overlap is relatively small. The parameters of the potential merger are summarised in the following table. The average values of past mergers were provided as a reference.

Table 11 about here

There are a number of factors favouring an easyJet/Vueling merger. Yet, Iberia, which owns $46 \%$ of Vueling, might want to prevented the acquisition and protect it home market. Whilst the analysis placed both Vueling and Norwegian as merger targets, the very high degree of business model similarity might suggest that these smaller carriers might consider a merger of equals, although a recent large order of both narrow body and wide body aircraft by Norwegian suggests 
the airline is seeking to grow organically. The difference in fleet may provide an insurmountable barrier in the path.

\section{Conclusion}

This paper has looked at LCC M\&A activity to examine whether they are fundamentally different from mergers between full services carriers. The in-depth interviews with industry experts confirmed that the reasons for mergers of LCCs and that the challenges such events pose are largely the same as mergers between full service carriers. The analysis of the previous M\&A events has also shown that there are no real differences in the relative position of target to its acquirer. Whilst merger and acquisition strategies for European low cost carriers will clearly go on behind closed doors, this paper has sought to develop a methodology by which likely partners could be identified and the likely success of any merger might be evaluated. The fit between merger partners' strategies and business culture was confirmed as being a key determinant the success of a merger. The POA approach has successfully been applied to as a tool to examine airline business models and the fit between potential partners. As the EU LCC market reaches maturity, it is likely that more mergers and acquisitions will occur. Having tools to assess the probable outcomes will be useful to analysts and investors.

\section{REFERENCES}

de Wit, J. and Zuidberg, J., ( 2012) The growth limits of the low cost carrier model.

Danklefsen, N. The Consequences Of The Growing European Low-Cost Airline Sector. Publication IP/B/TRAN/IC/2006-185, European Parliament, Policy Department Structural and Cohesion Policies, 2007.

Dobson, P. and Piga, C.A.G., ( 2009) Mergers and business model assimilation : evidence from low-cost airline takeovers, Loughborough.

Fageda, X., and J. Perdiguero ( 2011) An empirical analysis of a merger between a network and low-cost airlines, Xarxa de Referència en Economia Aplicada (XREAP) 2011-0518T12:19:20Z 2011-05-18T12:19:20Z 2011-05 2011-05.

FlightGlobal (2012) available at: www.flightglobal.com

Fragkogianni. (2012) Mergers \& Acquisitions in the airline industry at a European level (unpublished Presentation) Cranfield.

Francis, G., Humphreys, I., Ison, S. and Aicken, M., ( 2006) Where next for low cost airlines? A spatial and temporal comparative study.

Dobruszkes, F. (2006) An analysis of European low-cost airlines and their networks, Journal of Transport Geography, vol. 14, pp. 249-264.

Gaughan, P. A. (2011) Mergers, acquisitions and corporate restructurings/Patrick A. Gaughan, Hoboken, N.J. : Wiley; Chichester : John Wiley [distributor], 5th ed.

Graham, B. and Shaw, J., ( 2008) Low-cost airlines in Europe: Reconciling liberalization and sustainability.

Hanson, T., Neilson, G., Belin, S. (2002). Airline Merger Integration, Booz Allen \& Hamilton, accessed at:

http://pages.stern.nyu.edu/ igiddy/mergerdocuments/airline_merger_integration.pdfHealy, 
K. T. (1962) The Merger Movement in Transportation, American Economic Review, vol. 52, no. 2 , pp. 436.

Iatrou, K. Oretti, M. (2007). Airline Choices for the Future, Ashgate, Aldershot UK

Maruna, M. (2008) Importance of post-merger integration for the overall success of airline mergers, Unpublished thesis, Cranfield University

Mason, K. J. and Alamdari, F. (2007) EU network carriers, low cost carriers and consumer behaviour: A Delphi study of future trends, Journal of Air Transport Management, vol. 13, pp. 299-310.

Mason, K. J. and Morrison, W. G. (2009) Towards a means of consistently comparing airline business models with an application to the 'low cost' airline sector, Research in Transportation Economics, vol. 24, pp. 75-84.

Mason, K., Morrison, W.G., and I. Stockman (2013) Liberalization of Air Transport in Europe and the Evolution of 'Low-cost' Airlines in Forysth, P., Gillen, D., Huschelrath, K., Niemeier, H-M., and Wolf, T (eds) Liberalization in Aviation: Competition, Cooperation and Public Policy, Ashgate, Aldershot.

Merkert, R. and Morrell, P. S. (2012) Mergers and acquisitions in aviation - Management and economic perspectives on the size of airlines, Transportation Research Part E, vol. 48, pp. 853-862.

Sudarsanam, S., ( 2003) Creating value from mergers and acquisitions : the challenges ; an integrated and international perspective, Harlow [u.a.].

Tickle, B. W. (1987) A methodology for screening and identifying potential partners for growth through merger in air transport: And a case study of the UK industry, unpublished thesis, Cranfield University.

Wang, P. (2012) Empirical Evidence of Airline Merger Waves Based on A Selective Entry ModelDuke University, Durham. 


\begin{tabular}{|c|c|c|}
\hline Year & Partners & TYPE \\
\hline 1993 & Southwest Airlines/Morris Air & LCC \\
\hline 1997 & Valujet Airlines/AirTran & LCC \\
\hline 1997 & British Airways/Delta Air * & FSC \\
\hline 1998 & Delta Air Lines/Atlantic Southeast & FSC \\
\hline 1998 & American Airlines/Reno Air & FSC \\
\hline 1999 & Delta Air Lines/Comair Inc. & FSC \\
\hline 1999 & American Airlines/TWA & FSC \\
\hline 2002 & Ryanair/Buzz & $\mathrm{LCC}$ \\
\hline 2002 & easyJet/Go Fly & LCC \\
\hline 2004 & Copa Airlines/Aerorepublica & FSC \\
\hline 2004 & Air France/KLM & FSC \\
\hline 2004 & Atlantic Southeast/SkyWest Airlines & FSC \\
\hline 2004 & Deutsche BA/Germania & LCC \\
\hline 2005 & Lufthansa/Brussels Airlines & FSC \\
\hline 2005 & US Airways/America West Airlines & FSC \\
\hline 2005 & Maersk Air/Sterling & LCC \\
\hline 2005 & Republic Airways/Shuttle America* & FSC \\
\hline 2006 & airberlin/Deutsche $B A$ & LCC \\
\hline 2006 & BA Connect/Flybe & LCC \\
\hline 2007 & Avianca/Taca & FSC \\
\hline 2007 & Norwegian/FlyNordic & LCC \\
\hline 2007 & easyJet/GB Air & LCC \\
\hline 2007 & airberlin/LTU & LCC \\
\hline 2007 & Indian Airlines/Air India & FSC \\
\hline 2008 & Lufthansa/BMI British Midland & FSC \\
\hline 2008 & Lufthansa/Austrian & FSC \\
\hline 2008 & Delta Air Lines/Northwest Airlines & FSC \\
\hline 2008 & Republic Airline/Midwest Airlines & FSC \\
\hline 2008 & ClickAir/Vueling Airlines & $\mathrm{LCC}$ \\
\hline 2008 & Kingfisher/Air Deccan & FSC \\
\hline 2009 & Republic Airline/Frontier & FSC \\
\hline 2009 & China Eastern Airlines/Shanghai Airlines & FSC \\
\hline 2010 & TAM/Lan Airlines & FSC \\
\hline 2010 & British Airways/Iberia & FSC \\
\hline 2010 & United Airlines/Continental & FSC \\
\hline 2010 & GOL/Webjet & LCC \\
\hline 2011 & Southwest Airlines/AirTran & $\mathrm{LCC}$ \\
\hline 2011 & Skyways/City Airlines * & FSC \\
\hline 2011 & TRIP/Azul Airlines & LCC \\
\hline
\end{tabular}

*Mergers dropped from analysis due to lack of data 
Table 1: European regions and countries

\begin{tabular}{llc}
\hline Region & \multicolumn{1}{c}{ Countries included } & $\begin{array}{c}\text { Share } \\
\text { of seats }\end{array}$ \\
\hline Iberia & Gibraltar, Portugal, Spain \& Canary Island & $16 \%$ \\
France & Belgium, France, Luxembourg, Monaco, Netherlands, Switzerland & $16 \%$ \\
Germany & Austria, Germany & $16 \%$ \\
UK & Ireland, United Kingdom & $15 \%$ \\
Italy & Greece, Italy, Malta & $14 \%$ \\
Eastern & Albania, Armenia, Azerbaijan, Bosnia \& Herzegovina, Bulgaria, Belarus, Croatia, Czech & $12 \%$ \\
Europe & Republic, Estonia, Georgia, Hungary, Latvia, Lithuania, Macedonia, Moldova, \\
Scandinavia & Montenegro, Poland, Romania, Russian Federation, Serbia, Slovenia, Slovakia, Ukraine & $11 \%$ \\
\hline
\end{tabular}

Source: FlightGlobal, 2012 
Table 2: Weighting of benchmark items to profit

\begin{tabular}{|c|c|}
\hline Benchmark Item & $\begin{array}{c}\text { Profit correlation } \\
\text { Weights }\end{array}$ \\
\hline Unit cost (per ASK) Euro cent & 0.34 \\
\hline Yield per RPK (Euro cent) & -0.08 \\
\hline Operating revenue per sector (Euro) & -0.17 \\
\hline Average fare paid (Euro) (including ancillary revenue) & -0.27 \\
\hline Network density - departures per airport per day & 0.24 \\
\hline Routes offered & 0.34 \\
\hline All destinations available at airports served Weighted average & -0.10 \\
\hline Average weekly frequency per route & 0.07 \\
\hline Airport location - average distance from nearest population centre $(\mathrm{km})$ & -0.12 \\
\hline Flights at primary airports $(\%)$ & -0.07 \\
\hline OTP Punctuality $(\%)$ & 0.00 \\
\hline Passengers per flight & -0.39 \\
\hline Passengers per flight and cabin-crew members & -0.68 \\
\hline Economy seat width (Inches) most pop a/c & -0.35 \\
\hline Economy seat pitch (Inches) most pop a/c & -0.01 \\
\hline Ticketing, sales, promotion per passenger (Euro) & 0.51 \\
\hline Aircraft utilization (aircraft hours per day) & -0.09 \\
\hline Most populous aircraft type/mark accounts for fleet (\%) & 0.16 \\
\hline Aircraft sectors per day & 0.05 \\
\hline Passenger per employee & 0.72 \\
\hline Employee per aircraft & 0.53 \\
\hline Personnel cost per ASK & 0.09 \\
\hline Flight and cabin crew/employees (\%) & 0.50 \\
\hline ASK per employee ('000) & 0.62 \\
\hline Percent of city pair routes are monopolies $(\%)$ & -0.02 \\
\hline Weighted average annual passenger at airports served (in millions) & 0.26 \\
\hline No of network airlines at destination & 0.42 \\
\hline Airport/en-route costs per passenger (Euro) & 0.31 \\
\hline Median HHI on capacity (seat) & 0.03 \\
\hline Average HHI on capacity (seat) & 0.05 \\
\hline Average number of competitors per route & 0.19 \\
\hline Capacity share of seats $(\%)$ & 0.01 \\
\hline Average city size served & -0.07 \\
\hline
\end{tabular}


Table 3: US LCCs' similarity matrix

\begin{tabular}{lccccccc} 
& Southwest & AirTran & JetBlue & Frontier & Spirit & Allegiant & Virgin \\
\hline Southwest & 0 & 22.8 & 22.9 & 29.5 & 33.1 & 44.5 & 35.8 \\
AirTran & 22.8 & 0 & 15.4 & 28.7 & 22.2 & 32 & 28.2 \\
JetBlue & 22.9 & 15.4 & 0 & 30.2 & 22.4 & 29.8 & 23.2 \\
Frontier & 29.5 & 28.7 & 30.2 & 0 & 34.6 & 47.5 & 22.5 \\
Spirit & 33.1 & 22.2 & 22.4 & 34.6 & 0 & 17 & 28.1 \\
Allegiant & 44.5 & 32 & 29.8 & 47.5 & 28.1 & 41.7 & 0 \\
Virgin & 35.8 & 28.2 & 23.2 & 22.5 & 21.7 \\
\hline
\end{tabular}

Table 4: Size parameters of past LCC mergers

\begin{tabular}{|c|c|c|c|c|c|c|c|c|c|c|}
\hline Year & Acquirer & $\begin{array}{c}\text { OPS } \\
10^{3}\end{array}$ & $\begin{array}{c}\text { Seats } \\
10^{6}\end{array}$ & $\begin{array}{c}\text { ASK } \\
10^{9}\end{array}$ & Target & $\begin{array}{c}\text { OPS } \\
10^{3}\end{array}$ & $\begin{array}{c}\text { Seats } \\
10^{6}\end{array}$ & $\begin{array}{c}\text { ASK } \\
10^{9}\end{array}$ & Size ratio & Type \\
\hline 1993 & Southwest & 594 & 77 & 48 & Morris Air & 36 & 5 & 4 & 0.06 & \\
\hline 2011 & GOL & 294 & 49 & 45 & Webjet & 22 & 3 & 3 & 0.07 & Takeover \\
\hline 2007 & easyJet & 267 & 41 & 41 & GB Air & 21 & 3 & 7 & 0.09 & \\
\hline 2007 & Norwegian & 54 & 8 & 7 & FlyNordic & 10 & 2 & 1 & 0.17 & \\
\hline 2003 & Ryanair & 102 & 19 & 14 & Buzz & 20 & 2 & 2 & 0.18 & \\
\hline 2011 & Southwest & 1,156 & 162 & 173 & AirTran & 256 & 32 & 40 & 0.22 & \\
\hline 2007 & airberlin & 163 & 26 & 27 & LTU & 23 & 5 & 21 & 0.23 & \\
\hline 2006 & airberlin & 106 & 18 & 21 & DBA & 55 & 7 & 4 & 0.45 & Acquisition \\
\hline 1997 & Valujet & 42 & 5 & 3 & AirTran & 20 & 2 & 3 & 0.51 & \\
\hline 2004 & DBA & 33 & 5 & 2 & Germania & 18 & 2 & 2 & 0.55 & \\
\hline 2003 & easyJet & 87 & 13 & 10 & Go Fly & 53 & 7 & 7 & 0.61 & \\
\hline 2005 & Maersk Air & 23 & 3 & 3 & Sterling & 13 & 2 & 4 & 0.68 & \\
\hline 2012 & TRIP & 139 & 9 & 5 & Azul & 94 & 10 & 9 & 0.73 & \\
\hline 2009 & ClickAir & 52 & 8 & 7 & Vueling & 47 & 8 & 8 & 0.95 & Merger of equals \\
\hline 2006 & BA Connect & 93 & 6 & 4 & Flybe & 87 & 8 & 4 & 0.97 & \\
\hline
\end{tabular}


Table 5: Network overlap of historical LCC mergers

\begin{tabular}{lcccc}
\hline Partners & Airports & Routes & Seats & Network overlap \\
\hline Ryanair/Buzz & 0.02 & 0.00 & 0.00 & 0.01 \\
Norwegian/FlyNordic & 0.13 & 0.01 & 0.06 & 0.07 \\
easyJet/GB Air & 0.14 & 0.02 & 0.05 & 0.07 \\
airberlin/DBA & 0.25 & 0.01 & 0.03 & 0.10 \\
easyJet/Go Fly & 0.24 & 0.02 & 0.05 & 0.10 \\
Southwest/AirTran & 0.28 & 0.05 & 0.07 & 0.13 \\
Valujet/AirTran & 0.42 & 0.00 & 0.00 & 0.14 \\
Southwest/Morris Air & 0.28 & 0.12 & 0.07 & 0.16 \\
Maersk Air/Sterling & 0.23 & 0.13 & 0.19 & 0.18 \\
TRIP/Azul Airlines & 0.34 & 0.06 & 0.17 & 0.19 \\
airberlin/LTU & 0.35 & 0.14 & 0.10 & 0.20 \\
GOL/Webjet & 0.17 & 0.15 & 0.33 & 0.21 \\
BA Connect/Flybe & 0.27 & 0.05 & 0.38 & 0.23 \\
DBA/Germania & 0.25 & 0.07 & 0.49 & 0.27 \\
ClickAir/Vueling & 0.40 & 0.18 & 0.48 & 0.35 \\
\hline
\end{tabular}

Source: FlightGlobal, 2012

Table 6: Relative market share

\begin{tabular}{lllllllllll}
\hline Region & Leader & FR & U2 & AB & DY & VY & EI & W6 & BE & 4 U \\
\hline Iberia & FR & 1.66 & 0.40 & 0.23 & 0.04 & 0.53 & 0.05 & 0.03 & 0.00 & 0.02 \\
UK & FR & 1.10 & 0.91 & 0.01 & 0.04 & 0.01 & 0.36 & 0.08 & 0.49 & 0.02 \\
Germany & LH & 0.15 & 0.09 & 0.60 & 0.01 & 0.00 & 0.02 & 0.02 & 0.01 & 0.20 \\
Italy & AZ & 0.88 & 0.42 & 0.10 & 0.02 & 0.07 & 0.01 & 0.07 & 0.00 & 0.03 \\
France & AF & 0.26 & 0.45 & 0.05 & 0.01 & 0.07 & 0.04 & 0.02 & 0.02 & 0.01 \\
East Europe & SU & 0.54 & 0.17 & 0.06 & 0.08 & 0.02 & 0.03 & 0.75 & 0.01 & 0.09 \\
Scandinavia & $\mathrm{SK}$ & 0.17 & 0.03 & 0.03 & 0.66 & 0.00 & 0.00 & 0.03 & 0.01 & 0.00 \\
\hline
\end{tabular}

Table 7: Growth rate 2010/2011

\begin{tabular}{|c|c|c|c|c|c|c|c|c|c|}
\hline Region & FR & $\mathrm{U} 2$ & $\mathrm{AB}$ & DY & VY & EI & W6 & $\mathrm{BE}$ & $4 \mathrm{U}$ \\
\hline Iberia & $22 \%$ & $11 \%$ & $-29 \%$ & $13 \%$ & $6 \%$ & $-2 \%$ & $29 \%$ & $-19 \%$ & $11 \%$ \\
\hline UK & $-10 \%$ & $5 \%$ & $-30 \%$ & $28 \%$ & $-2 \%$ & $-4 \%$ & $17 \%$ & $-2 \%$ & $7 \%$ \\
\hline Germany & $-25 \%$ & $16 \%$ & $-8 \%$ & $6 \%$ & $-16 \%$ & $4 \%$ & $3 \%$ & $-21 \%$ & $-4 \%$ \\
\hline Italy & $18 \%$ & $7 \%$ & $-5 \%$ & $13 \%$ & $-4 \%$ & $4 \%$ & $8 \%$ & $-3 \%$ & $28 \%$ \\
\hline France & $0 \%$ & $44 \%$ & $1 \%$ & $2 \%$ & $28 \%$ & $7 \%$ & $5 \%$ & $21 \%$ & $3 \%$ \\
\hline East Europe & $5 \%$ & $8 \%$ & $5 \%$ & $-8 \%$ & $17 \%$ & $-12 \%$ & $12 \%$ & $\mathrm{x} 5$ & $-15 \%$ \\
\hline Scandinavia & $0 \%$ & $13 \%$ & $-1 \%$ & $16 \%$ & $0 \%$ & $2 \%$ & $14 \%$ & $\mathrm{x} 25$ & $-2 \%$ \\
\hline
\end{tabular}


Table 8: Summary of motives

\begin{tabular}{|c|c|c|c|c|c|}
\hline Airline & $\begin{array}{l}\text { Merger } \\
\text { Motive }\end{array}$ & $\begin{array}{l}\text { Competitive } \\
\text { advantage }\end{array}$ & $\begin{array}{l}\text { Operating } \\
\text { ratio } \\
(2011) \\
\end{array}$ & $\begin{array}{c}\text { Aggregate } \\
\text { Op.margin } \\
(2008-2011) \\
\end{array}$ & $\begin{array}{l}\text { Potential merger } \\
\text { role }\end{array}$ \\
\hline Ryanair & $\begin{array}{l}\text { Market } \\
\text { access }\end{array}$ & $\begin{array}{l}\text { Strong } \\
\text { position }\end{array}$ & $116 \%$ & $11.90 \%$ & Acquirer \\
\hline easyJet & $\begin{array}{l}\text { Strengthen } \\
\text { position }\end{array}$ & $\begin{array}{l}\text { Strong } \\
\text { position }\end{array}$ & $108 \%$ & $5.14 \%$ & Acquirer \\
\hline airberlin & $\begin{array}{l}\text { Strengthen } \\
\text { position }\end{array}$ & Germany & $94 \%$ & $-1.58 \%$ & $\begin{array}{l}\text { Acquirer } \\
\text { / Partner }\end{array}$ \\
\hline Norwegian & Growth & Scandinavia & $104 \%$ & $2.53 \%$ & $\begin{array}{l}\text { Partner } \\
\text { / Target }\end{array}$ \\
\hline Vueling & Growth & Iberia & $101 \%$ & $3.98 \%$ & Target \\
\hline Aer Lingus & Niche & Long-haul & $104 \%$ & $1.61 \%$ & Target \\
\hline WIZZ Air & Growth & East Europe & $100 \%$ & Not available & Target \\
\hline flybe & Niche & Aircraft size & $100 \%$ & $-1.06 \%$ & Target \\
\hline germanwings & Niche & $\begin{array}{l}\text { Lufthansa } \\
\text { Group }\end{array}$ & $93 \%$ & $-3.10 \%$ & $\begin{array}{l}\text { LH asset } \\
\text { realisation }\end{array}$ \\
\hline
\end{tabular}

Source: Financial data - FlightGlobal, 2012

Table 9: Europe LCCs' similarity matrix

\begin{tabular}{lccccccc}
\hline & Ryanair & easyJet & Norwegian & Vueling & flybe & Aer Lingus & airberlin \\
\hline Ryanair & 0 & 23.3 & 32.5 & 32 & 46.3 & 45.8 & 35.5 \\
easyJet & 23.3 & 0 & 15 & 13.1 & 36.8 & 33.7 & 22.5 \\
Norwegian & 32.5 & 15 & 0 & 8.8 & 37.2 & 24.9 & 22.5 \\
Vueling & 32 & 13.1 & 8.8 & 0 & 40.2 & 32.3 & 28.2 \\
flybe & 46.3 & 36.8 & 37.2 & 40.2 & 0 & 29.2 & 31.1 \\
Aer Lingus & 45.8 & 33.7 & 24.9 & 32.3 & 29.2 & 0 & 26.3 \\
airberlin & 35.5 & 22.5 & 22.5 & 28.2 & 31.1 & 26.3 & 0 \\
\hline
\end{tabular}


Table 10: easyJet/Norwegian/Vueling benchmark differences

\begin{tabular}{lccccc}
\hline Benchmark & U2 & DY & VY & U2/DY & U2/VY \\
\hline Profit & 9.3 & 9.0 & 8.8 & 0.3 & 0.6 \\
Cost & 7.6 & 6.9 & 6.9 & 0.7 & 0.6 \\
Revenue & 5.9 & 6.8 & 5.7 & 0.8 & 0.2 \\
Connectivity & 7.7 & 3.2 & 4.0 & 4.5 & 3.7 \\
Convenience & 8.7 & 7.0 & 8.5 & 1.7 & 0.2 \\
Comfort & 4.2 & 5.2 & 3.1 & 1.0 & 1.0 \\
Distribution & 7.7 & 10.0 & 10.0 & 2.3 & 2.3 \\
Aircraft & 10.0 & 9.2 & 9.9 & 0.9 & 0.1 \\
Labour & 8.1 & 8.1 & 9.2 & 0.0 & 1.2 \\
Airport & 6.3 & 3.7 & 4.0 & 2.6 & 2.3 \\
Market & 6.4 & 6.6 & 5.5 & 0.3 & 0.9 \\
Overall difference & - & - & - & 15.0 & 13.1 \\
\hline
\end{tabular}

Table 11: easyJet/Vueling merger parameters

\begin{tabular}{lcc}
\hline Parameter & easyJet/Vueling & Average \\
\hline Acquirer Size & 533 & 271(LCCs) 569 (FSCs) \\
Target Size & 124 & 65 (LCCs) 183 (FSCs) \\
Size ratio & 0.2 & 0.42 \\
Airports overlap & 0.32 & 0.26 \\
Routes overlap & 0.03 & 0.07 \\
Seats overlap & 0.06 & 0.15 \\
Network overlap & 0.14 & 0.15 \\
\hline
\end{tabular}


Figure 1: Product and Organisation Architecture: Southwest/AirTran

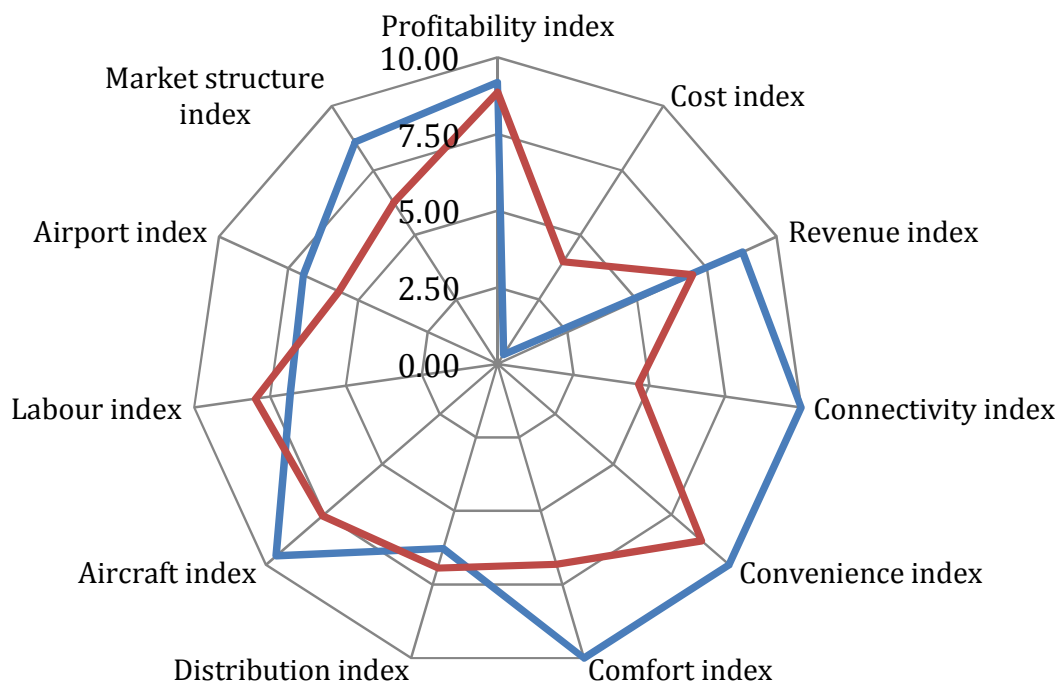

- Southwest $\quad$ AirTran

Figure 2: Reasons for LCCs to merge

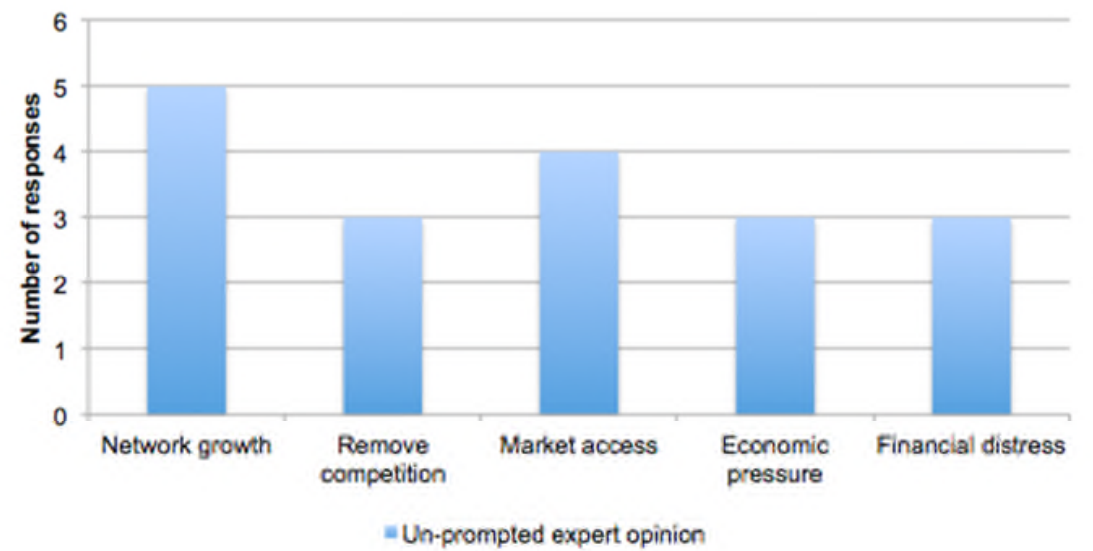


Figure 3: Key characteristics of potential M\&A target/partner

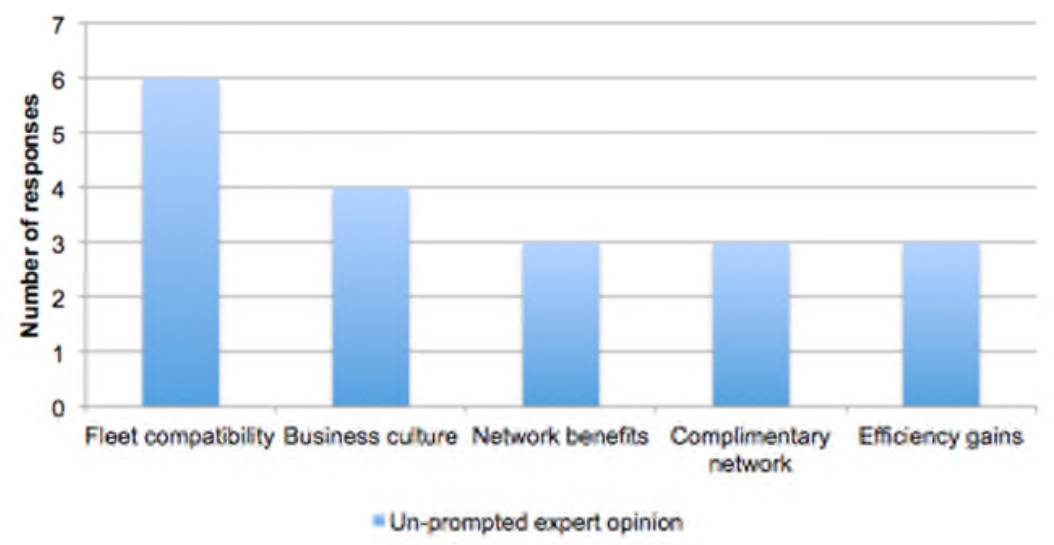

Figure 4 : European LCC Sector Graph (Braxton Approach)

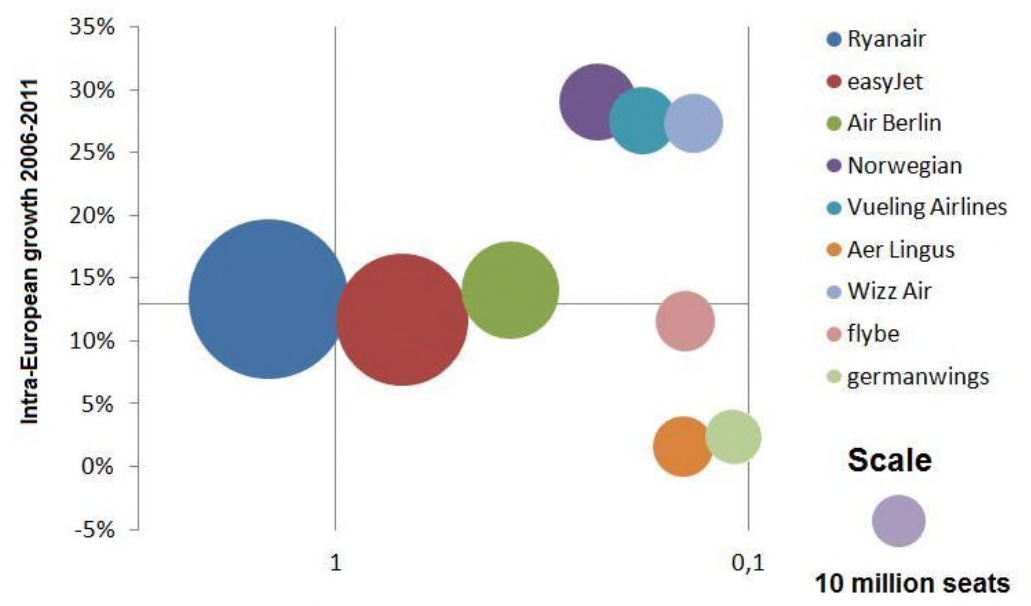

Relative market share

Figure 5: Ryanair Product portfolio matrix (BCG)

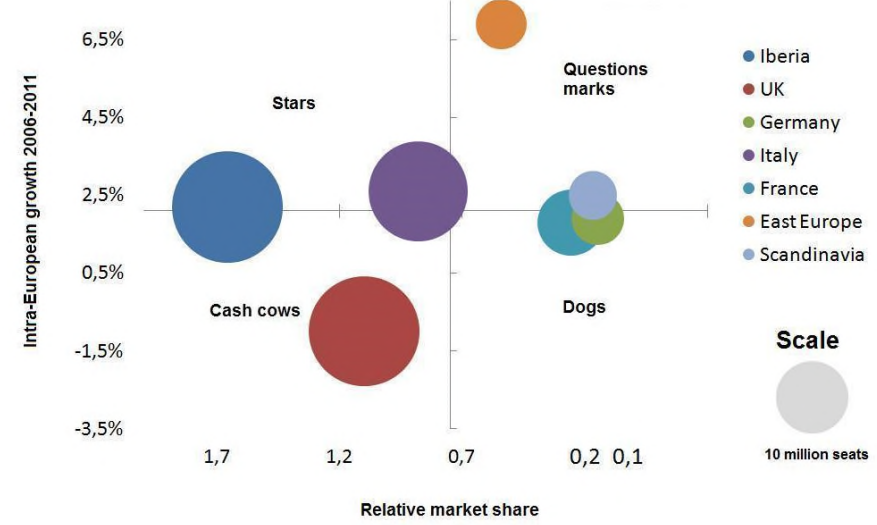


Figure 6: easyJet Product portfolio matrix (BCG)

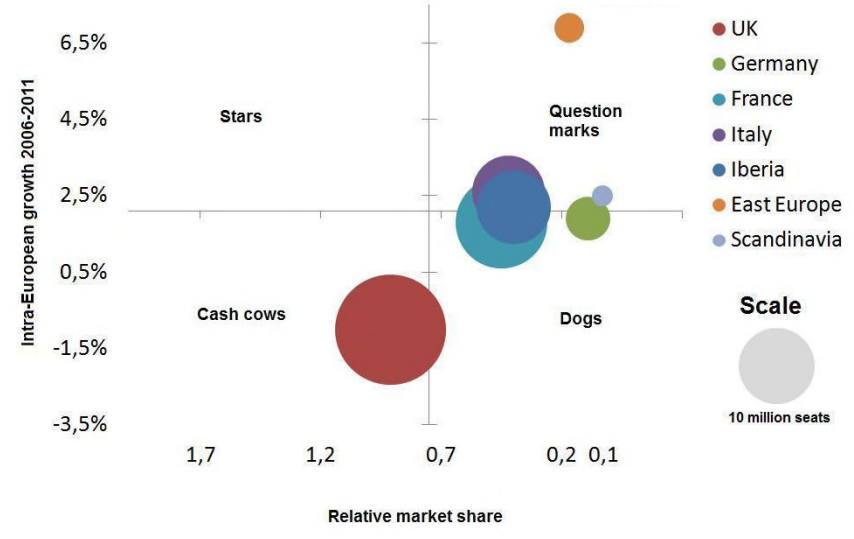

Figure 7: Other LCCs Product portfolio matrix

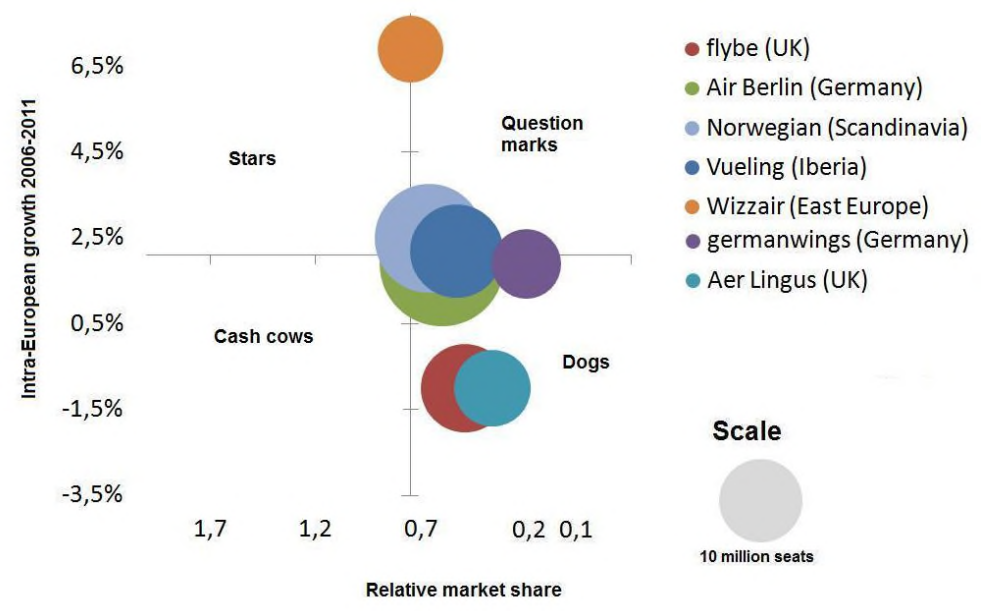


Figure 8: Product and Organisation Architecture: easyJet/Norwegian/Vueling

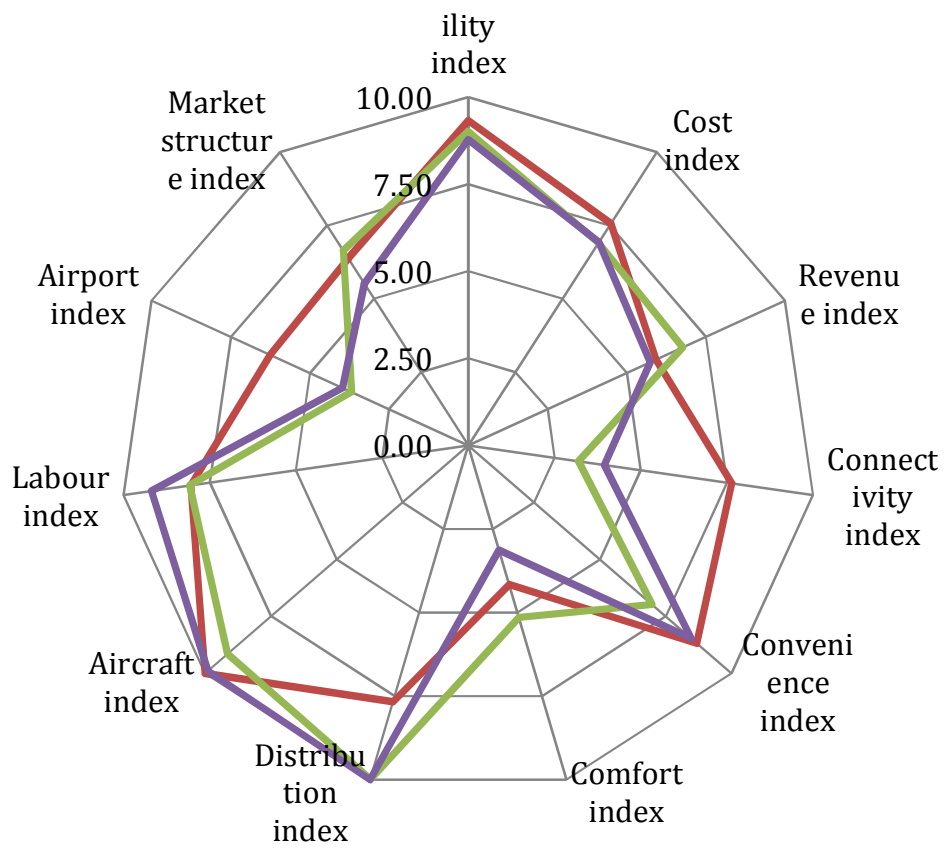

—easyJet $\longrightarrow$ Norwegian $\longrightarrow$ Vueling Airlines 